\title{
Agenesis of the septum pellucidum
}

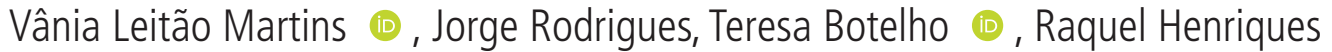

Department of Neonatology A, Maternidade Dr Daniel de Matos, Centro Hospitalar e Universitario de Coimbra EPE, Coimbra, Portugal

\section{Correspondence to} Dr Vânia Leitão Martins; vaniamartins20@gmail.com

Accepted 16 December 2020

\section{DESCRIPTION}

We describe the case of a female infant born of a term pregnancy ( 38 weeks) with regular surveillance and course, despite the mother having class III obesity and gestational diabetes controlled with insulin. During pregnancy, the mother had three fetal ultrasounds, all with normal morphology and biophysical profiles. She was delivered by emergency caesarean section and needed resuscitation with respiratory support and admission to our neonatal intensive care unit at birth. The Apgar score was 4, 9, 9 at 1, 5 and $10 \mathrm{~min}$, respectively. Blood gas analysis showed metabolic acidosis at 1 hour of life. She did not fulfil criteria for therapeutic hypothermia. She started treatment with ampicillin and gentamycin for clinical signs of sepsis on day 3, interrupting treatment after 5 days due to negative blood cultures. During the first week of life, she experienced paroxysmal events suggestive of

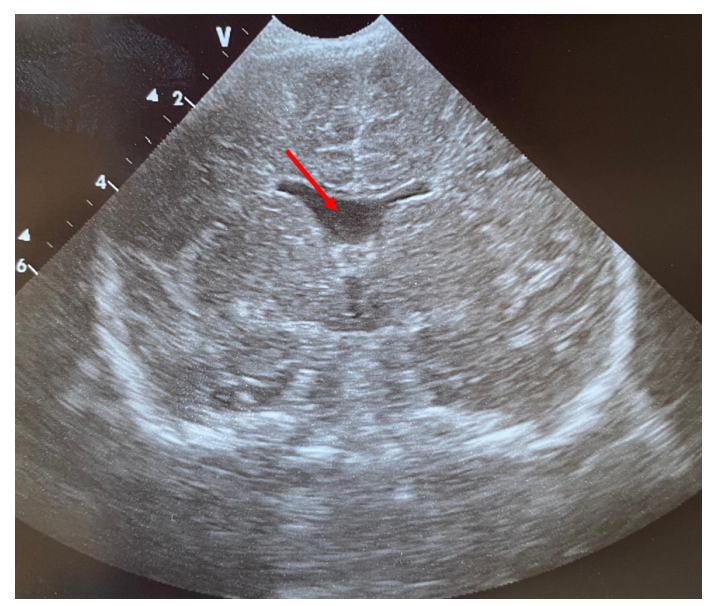

Figure 1 Transfontanellar ultrasound performed on the second day of life, in which the pellucid septum is absent (arrow).

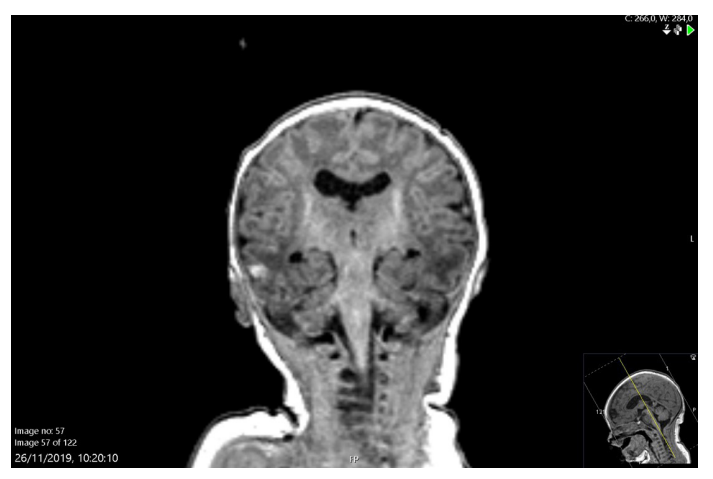

Figure 2 MRI on day 11 confirmed agenesis of the pellucid septum. seizure, which subsided without need for treatment. Neurological examination at the time exhibited hypotonia and cortical thumb sign. Transfontanellar ultrasound (TF) on the first day of life suggested the presence of agenesis of the septum pellucidum (ASP) (figure 1) without other changes. Brain MRI on day 11 (figure 2) confirmed ASP and small corticosubcortical haemorrhagic foci without other associated malformations. Electroencephalogram exhibited infrequent paroxysmal activity in temporoparietal regions with no record of electrographic or electroclinical crisis. She was discharged after 29 days without abnormalities on physical examination. Currently, at 9 months old, she presents normal growth and neurological development and there were no episodes suggestive of seizure nor other complications since discharge.

The septum pellucidum is part of the limbic system, formed during the eighth week of pregnancy. The absence of this structure is a rare condition (general prevalence of 2 to 3 in 100000 individuals) and can be partial or complete, congenital or acquired. ${ }^{1-3}$ It may occur isolated or associated with other conditions, such as agenesis of the corpus callosum,

\section{Patient's perspective}

My experience with this problem was maddening. It was one of the worst experiences of my life, as I learnt about the malformation after a day and a half in labour and an emergency caesarean section. To make matters worse the baby was born with sepsis. I have to thank all the maternity hospital and intensive care unit personnel, who have always been very professional with me. Despite everything, she is a completely normal baby with a lot of energy. 
septo-optic dysplasia, Arnold-Chiari malformation, schizencephaly or holoprosencephaly. ${ }^{13-5}$ Prognosis depends on the clinical presentation and associated anomalies, and information from fetal or postnatal MRI proves to be essential. Published literature suggests mostly favourable developmental prognosis for isolated absent septum pellucidum. ${ }^{45}$ Nevertheless, follow-up by Neurology, Endocrinology and Ophthalmology is recommended. ${ }^{2}$ The described condition requires regular follow-up, in order to allow the anticipation and early recognition of signs or symptoms liable to intervention. Suspicion of ASP on prenatal or TF ultrasound must be excluded by prenatal or postnatal MRI, which are also essential to exclude other associated malformations. In our case, it was an incidental finding in a TF ultrasound performed due to concern for neonatal seizures and need for extensive resuscitation at birth. Although the exact aetiology of the small haemorrhagic lesions is unknown, we believe that they were probably related to hypoxic injury and not to the subject's absent septum pellucidum. Maternal biotype may have played a part for the fact that this finding was not evident in routine obstetric ultrasounds.

Twitter Jorge Rodrigues @mrdraperjr
Contributors All authors have participated in the drafting of the manuscript and have approved its final version. VLM and JR participated in the research of clinical data and wrote the text together. TB did the interview with the mother and gave information to the patient's mother to obtain patient consent. She also contributed to the revision of the discussion. $\mathrm{RH}$ reviewed the text and corrected errors and selected the images in the article.

Funding The authors have not declared a specific grant for this research from any funding agency in the public, commercial or not-for-profit sectors.

Competing interests None declared.

Patient consent for publication Parental/guardian consent obtained.

Provenance and peer review Not commissioned; externally peer reviewed.

\section{ORCID iDs}

Vânia Leitão Martins http://orcid.org/0000-0001-9846-4679

Teresa Botelho http://orcid.org/0000-0002-2884-9685

\section{REFERENCES}

1 Ben M'Barek I, Tassin M, Guët A, et al. Antenatal diagnosis of absence of septum pellucidum. Clin Case Rep 2020;8:498-503.

2 Vawter-Lee MM, Wasserman H, Thomas CW, et al. Outcome of isolated absent septum pellucidum diagnosed by fetal magnetic resonance imaging (MRI) scan. J Child Neurol 2018:33:693-9.

3 Scoffings DJ, Kurian KM. Congenital and acquired lesions of the septum pellucidum. Clin Radiol 2008;63:210-9.

4 Ognean ML, Boantă O. Agenesis of the septum pellucidum. Neonatology 2011;2:40-3.

5 Rennie JM, Hagmann CF, Robertson NJ, eds. Neonatal Cerebral Investigation. Cambridge, United Kingdom: Cambridge University Press, 2008.

Copyright 2021 BMJ Publishing Group. All rights reserved. For permission to reuse any of this content visit https://www.bmj.com/company/products-services/rights-and-licensing/permissions/

BMJ Case Report Fellows may re-use this article for personal use and teaching without any further permission.

Become a Fellow of BMJ Case Reports today and you can:

- Submit as many cases as you like

- Enjoy fast sympathetic peer review and rapid publication of accepted articles

- Access all the published articles

Re-use any of the published material for personal use and teaching without further permission

Customer Service

If you have any further queries about your subscription, please contact our customer services team on +44 (0) 2071111105 or via email at support@bmj.com.

Visit casereports.bmj.com for more articles like this and to become a Fellow 